\title{
O ESPAÇO DA ÉTICA NA EDUCAÇÃO FÍSICA ${ }^{1}$
}

Artigo Convidado

Silvino Santin

Universidade Federal de Santa Maria

RESUMO: Este estudo apresenta como tema central a ética, acompanhada das discussões sobre profissionalismo e produção do conhecimento. A abrangência do tema abre portas para muitos ingressos, seja para sublinhar diferentes aspectos, seja para desenvolver diferentes compreensões ou metodologias. A opção, aqui apresentada, privilegiou o tema da ética inserido no espaço da educação física. O profissionalismo e a produção do conhecimento são partes fundamentais no espaço da educação física, evidentemente, descritos a partir da ética. A referência primeira para a apresentação dos temas é a filosofia, ou, melhor dito, um exercício de filosofar. Para isso, são tratadas duas questões principais: o que se entende quando se fala a palavra ética? E o que se precisa saber para que a ética possa ocupar um espaço na educação física?

Palavras-chave: Ética. profissionalismo. prudução do conhecimento. Educação Física.

${ }^{1}$ Este trabalho foi apresentado na Semana Científica da Faculdade AGES, na Bahia, com o título Ética, Profisisionalismo e Produção do Conhecimento. 


\section{ÉTICA}

\section{Sobre as questões}

Antes de responder às duas perguntas citadas no resumo deste aetigo, vou repetir uma anedota que envolve o filósofo da ciência, Gastão Bachelard (1884-1962). Esse pensador francês, já no fim da vida, estava sendo entrevistado por um jornalista. Depois de alguns minunos, Bachelard o interrompeu: "O senhor, manifestamente, vive em um apartamento e não em uma casa." E o jornalista surpreso, perguntou-Ihe o que queria dizer com isso. O filósof Ihe respondeu "que a diferença entre uma casa e um apartamento é que a primeira possui, além da área de habitação, um sótão e um porão; e o que há de particular, acrescentou, é que sempre subimos ao sótão, e descemos ao porão". A explicação: o sótão, segundo Bachelard, significa, para nós humanos, o espaço onde se "vive a busca de significações da existência por meio de símbolos filosóficos, poéticos, artísticos, religiosos, etc". A descida ao porão, ao contrário, exige, por vezes, "olhar o que se passa nos subsolos e fundamentos psicológicos ou sociais de nossa existência e discernir nos condicionamentos o que nos oprime e libera". ${ }^{2}$

A partir dessas explicações podemos estabelecer, ainda que de maneira simplificadora, duas atitudes para formular a questão da ética. A primeira atitude, a mais habitual, consiste em adotar uma definição, tirada de dicionários ou enciclopédias, de preferência mais atual e aceita pelos teóricos e pesquisadores. Por exemplo, "Ética é a ciência da moral ou a arte de orientar o comportamento". Outra definição, ainda na primeira atitude e no domínio dos conceitos, muito presente na filosofia acadêmica, entende que a ética "é a ciência que visa estudar os valores, universalmente legitimados, fundadores de todas as relações humanas em qualquer esfera em que acontecem". ${ }^{3}$ Pode-se, também, lembrar uma definição distintiva entre ética e moral apresentada por Roberto Andorno: "Distinque-se a ética, fundada sobre a razão, da moral, que tem uma conotação religiosa". ${ }^{4}$

A segunda atitude, afastando-se das definições conceituais, adota uma metodologia descritiva inspirada na fenomelogia de Edmund Husserl (1859-1938)l, especialmente 
quando declara que "o real existe para descrever, e não para construir ou para constituir". E, mais adiante, reforça a idéia afimando que "não se trata de explicar nem de analisar, mas de descrever". ${ }^{5}$ Inspirado nestas afirmações, Maurice Merleau-Ponty (1908-1961) sublinha que a primeira recomendação dada por Husserl à filosofia desde o início de ser uma "psicologia descritiva" ou de voltar "às coisas mesmas" é em primeiro lugar uma reprovação da ciência. ${ }^{6}$ Isto não significa uma negação das ciências, mas um apelo para ir além de definições, conceitos e teorias. O caminho seria nosso enfretamento imediato com o real ou o fenômeno. Fomos habitados a estudar o real através dos conceitos.

Neste contexto, a segunda atitude é mais ampla, ela busca os fundamentos que constituem a ciência ética. Para isso trilha o caminho das suas origens, isto é, uma descida ao porão. Portanto, nada melhor do que lembrar a definição mais descritiva do que conceitual, apresentada por Jean Bernard: "A ética implica uma reflexão sobre os comportamentos e começa a existir com Aristóteles. E esta palavra sábia, em oposição a seu equivalente "moral", supõe que se interrogue sobre os princípios e que se discuta isso. A palavra, portanto, reflete esse maravilhoso esforço de lucidez que caracteriza então o pensamento grego. A ética é a expressão da medida. É a garantia da harmonia que resulta da boa conduta da alma e que determina o lugar certo de qualquer coisa (de qualquer ato) no mundo."

Nas pesquisas e estudos fenomenológicos, a história merece um papel fundamental. Em relação à ética, não é preciso muito esforço para confirmar esse fato. É suficiente ler com atenção as definições de ética para verificar que, tanto as definições quanto as preocupações com a compreensão da questão ética remontam à Grécia antiga. Este dado, aparentemente, não provoca maiores questionamentos nem curiosidades. Em geral, é aceito sem prestar atenção sobre as vinculações da ética com a Polis grega, digamos, com a civilização grega. Aliás, sempre que se procura entender o universo cultural ocidental, em qualquer dimensão, acaba-se chegando às raízes gregas. 


\section{Primeiro momento}

Para iniciar entender a questão da ética, segundo uma velha recomendação, frequentemente veiculada pelos professores de filosofia, deve-se consultador um bom dicionário etimológico e, em seguida, um bom dicionário de fiolsofia. As duas fontes recomendadas coincidem afirmando que "o conceito de ética remonta à Grécia antiga". E se origina de "ethos", que significa modos de ser. Jean Bernard, por sua vez, busca o detalhe de que "ethos" em grego possue duas grafias, uma com "eta" (e longo), outra com "épsilon" (e breve), com significados complementares. Na primeira grafia - com "eta" - "éthos" "significa "o conjunto de hábitos, dos comportamentos cuja enraizamento gera uma segunda natureza." Na grafia - com épsilon - significa o lugar habitual (por exempol o sol tem o seu lugar no Oriente, a Leste, quando se levanta. Por extensão, significa o lugar correto de todas as coisas". 8

O lugar correto de cada coisa ou de cada ser está inscrito na natureza presente em cada um. Para Platão, em sua obra Politéia (República de Platão), cada ser se comporta segundo sua natureza. Por exemplo, para o cão de guarda, a agressividade lhe é natural. No caso dos seres humanos quem determina seu comportamento é sua psíche que se apresenta de forma diferente, na seguinte ordem: a racional, instalada na cabeça; a irascível, instalada no peito; a concupiscivel, instalada no abdome estabelecendo tres classes sociais, respectivamente, a dos filósofos, a dos guerreiros e a dos produtores. ${ }^{9}$ A proposta platônica revela uma nítida dependência da ética com a organização social gerga.

Voltando à dupla interpretação etimológica de Jean Bernard, fica demonstrado que todos os debates sobre os fundamentos universais da ética começam inevitavelmente sobre a natureza de cada ser. No curso da história, entretanto, com a evolução das ciênicas e o desenvolvimento das organizações sociais, surgiram várias transformações.

A ética, como exigência necessária para definir a vida humana invidual e coletiva, esteve presente desde o início do pensamento grego, definido como filosofia. Esta vinculação umbilical entre ética e filsofia pode ser observada nos antigos dicionários e enciclopédias, como tema reservado à linguagem dos filósofos. Na linguagem, diga-se menos filosófica, a palavra moral ocupou o seu lugar e, durante muito tempo, foi a única empregada para

\footnotetext{
${ }^{8}$ Bernard, Jean. Op. Cit. P.25.

${ }^{9}$ Platão, Diálogo de Fedro e República. Edições de Ouro.
} 
designar os valores que regem o comportamento humano. Hoje, a ética voltou com intesidade e passou a designar a ciência da moral. E não parou aqui, sua tragetória inovadora continua apresentando novas possibilidades de fundamentação.

\section{Segundo momento}

Após o término do período áureo da filosofia grega, a ética, definida como modo de ser de cada ser, passou por um longo período de identificação com a moral. Já não se discutia os fundamentos da eticidade, mas procurava-se estabelecer regras comportamentais ou das relações sociais.

$\mathrm{Na}$ passagem da eticidade para a moralidade, resumindo muito superficialmente, encontramos dois períodos. O período da jurisprudência romana consolidada pelo código de direito que se compõem de duas instâncias, a do direito natural e a do direito positivo.

O direito natural é herança da filosofia grega. Para a jurisprudência romana o Direito Natural consitiria numa consciência pré-existente na mente do ser humano que permitiria distinguir o correto do incorreto, o bem do mal, o justo do injusto. Tal consciência seria o fundamento e a justificativa para estabelecer o direito positivo como explicitação prática do direito natural e como garantia do convívio social em nome de três princípios: "não lesar o outro, viver honestamente e dar a cada um o que é seu".

O segundo período abrange toda a Idade Média. A predominância é da moral teológica. As teologias, seja do Cristianismo ou do Islamismo, desenvolveram uma ética divina. Deus é a única fonte inquestionável de eticidade. Aos homens cabe a tarefa de traduzi-la em regras e normas de vida pessoal e social. É o período em que os temas morais se sobrepõem às questões dos fundamentos da eticidade. Simples, o fundamento era inquestionável, Deus. O termo dominante passa a ser moralidade, como expressão da vontade divina. A moral, em última instância, era a regulamentação dos ensinamentos divinos que, geralmente, estava nas mãos das autoridades religiosas.

No afã de prescrever as minúcias dos costumes morais, surgiram as distorções expressas pelos moralismos e pelos moralistas. Apenas para lembrar, o historiador e filósofo medievalista, Jacques Le Goff (1924-2014), projetou novas luzes sobre a Idade Média, que, no entender dele, se estendeu do século V até a Revolução Francesa 1789. Época em que vigorou a moral, baseada na teologia cristã para as culturas européias. 


\section{Terceiro momento}

A revolução científica, iniciada com Galileu Galilei (1564-1642), inaugura uma nova maneira de fazer ciência. Os livros, sagrados ou nem tanto, aceitos, até então, como fontes inquestionáveis de conhecimento, devem ser substituídos, segundo Galileu, pelo único livro de cientificidade, o universo, escrito com caracteres matemáticos e figuras geométricas. Cabe ao homem ler esse livro através da Razão. Estava aberto, também, o caminho para uma nova eticidade. O raciocínio ficou claro, se a razão é a faculdade capaz de interpretar o universo, será, também, competente para fundamentar uma nova ética.

Em relação à construção de conhecimentos, Renê Descartes (1596-1650) estabelece os rumos da nova cientificidade com a obra, Discurso sobre o Método. Essa orientação é seguida por uma parcela expressiva de pensadores até Husserl que dedicaram obras fundamentais sobre a capacidade das faculdades mentais de conhecer a realidade.

Em relação ao estabelecimento de novos fundamentos da ética, entre outras obras, pode-se citar, em primeiro lugar, A Ética demonstrada segundo o costume (ordem) dos geômetras. ${ }^{10}$ Se a razão é capaz de construir conhecimentos, ela seria capaz, também, de fixar o fundamento da ética racional. Assim, racionalidade, além de se identificar com a cientificidade, identifica-se com a eticidade. Racionalidade é eticidade. Em segundo lugar, e certamente a mais expressiva é a obra de Kant (1724-1850), Crítica da Razão Prática, na qual proclama o famoso imperativo categórico, assim formulado: "Age de maneira tal que a máxima de tua ação sempre possa valer como princípio de uma lei universal."11 Entretanto, antes de fundamentar na razão os princípios gerais da ação humana, Kant dedicou-se, na Crítica da Razão Pura, ao estudo do conhecimento, investigando seus limites, suas possibilidades e suas aplicações. Com essas duas obras Kant tornou-se a referência fundamental para a Filosofia, seja no alcance da Razão para construir conhecimentos, seja na capacidade de definir os princípios de uma ética universal. O que pode ser contatado nos filósofos pós-kantiano, em particular, Jürgen Habermas, com sua obra, Moralbewusstsein und kommunikatives Handeln. ${ }^{12}$

\footnotetext{
${ }^{10}$ Espinosa, Baruch. Etica more geométrico demonstrata. Coleção Pensadores.

${ }^{11}$ Kant Emmanuel. Crítica da Razão Prática. Coleção Pensadores.

12 Habermas, Jürgen. Tradução: Consciência Moral e Agir Comunicativo. Rio de Janeiro: Tempo Brasileiro. 1989..Uma observação complementar: Ernest Tugendhat, autor do livro Vorlesungen über Ethik (Lições sobre Ética), do qual merece destaque, pela atualidade do tema, a Nona Lição com o título "A ética compaixão; animais, crianças, vida pré-natal. Petrópolis: Editora Vozes. 1993.
} 
Entretanto, apesar dos esforços em definir bases universalmente válidas para a ética, a questão sofre um duplo abalo, de um lado o esgotamento das filosofias racionalistas, de outro lado a impotência das ciências empíricas em incluir entre seus objetos a ética. Neste sentido, Henri Atlan, diante do que se ouve falar de que não acreditamos mais nas religiões, nem nas filosofias, somente na ciência, porque ela é bem-sucedida, portanto seria dever dos cientistas nos indicar como devemos viver, declara que "toda minha tentativa consiste em explicar em que esta exigência carece de fundamentos". ${ }^{13}$

As filosofias racionalistas não conseguiram demonstrar que a Razão é capaz de garantir uma eticidade universal. Não significa que agora teria surgido a condição de construir uma ética universal. Por enquanto, tudo indica que seria possível apresentar a raiz de universalidade em outro fundamento. A definição de uma ética universal, talvez, continue, ainda, um ideal distante.

\section{Quarto Momento}

O conhecimento científico, apesar das críticas e de seus limites, ainda continua responsável pelo avanço do debate ético. Isto porque não há uma negação das ciências, mas uma consciência de seus limites. Assim, a constatação de que as ciências empíricas, modeladas na Física e na Matemática, não conseguem resolver o fenômeno vida, a não ser reduzindo-a a um sistema de lógica físico/mecânica, provocou um número, cada vez maior, de cientista a se interrogarem sobre o excesso do poder da ciência. Assim, Gregory Bateson (1904-1980), antropólogo e biólogo, entre tantos outros, reclama da necessidade de pensar em outro modelo de lógica, ainda que não aceitáveis pela lógica da cientificidade dominante. "A vida, diz ele, provavelmente, nem sempre está interessada em saber o que é logicamente aceitável. Eu ficaria realmente surpreso se ela estivesse”. ${ }^{14}$ Henri Atlan (I931...), médico e biólogo, reconhece o conflito existente entre o conceito ou definição de vida, e a vida como fenômeno real. Ou seja, entre ousia (essência) vital e conceito, logos (palavra).

\footnotetext{
${ }^{13}$ Atlan, Henri. Henri Atlan, Teórico da Auto-Organização. Em Pessis-Pasternak, Guita. Do Caos à Inteligência Artificial. Campinas SP. UNESP,1993. P. 51-83. Nota: Título original: Faut-il Brüler Descartes? Du chãos à l'inteligence artificille: quand les scientifiques s'interrogent. (è preciso queimar Descartes? Do caos à inteligência artificial: quando os cientistas se interrogam).

${ }^{14}$ Bateson, Gregory, Os homens são como a Planta. A Biologia e uma Teoria do Conhecimento. Cap. 1 Os Homens são como a Planta. In Gaia - Uma Teoria do Conhecimento. Willian I. Thompson (Org.). São Paulo: Editora Gaia, 1990, p. 35-44.
} 
Neste sentido, retoma as palavras de Ganguilhem: "O conceito do ser vivo é, portanto, em última instância, o próprio ser vivo". ${ }^{15}$

O acentuado desenvolvimento na área das biologias, particularmente da biologia molecular e da genética, além de abrir caminho para o enfrentamento com as ciências empíricas, instaurou um novo modelo de interpretar o mundo da vida, Lebenswelt. As repercussões para o campo da ética foram imediatas. O primeiro passo aconteceu com o surgimento de um neologismo, BIOÉTICA. O termo, bioética, foi empregado, pela primeira vez, exatamente para superar os problemas criados pelo desenvolvimento tecnológico através de uma compreensão mais humanista superando a dicotomia entre as explicações científicas dos fatos e os valores, objetos da ética. O criador deste neologismo, Paul Max Fritz Jahr (1895-1953), o utilizou com o objetivo de provocar uma revisão do relacionamento ético dos homens em relação a animais e plantas ${ }^{16}$. Era, apenas, o começo de uma proposta de mudança da fonte de eticidade.

Nos Estados Unidos, a partir de 1970, o termo, bioética, foi utilizado para designar os relacionamentos entre o médico e o paciente. Tal emprego não foi bem aceito porque daria a entender que se tratava de biomedicina. Por isso, na Europa, preferiu-se falar de ética biomedical, em lugar de bioética. Nos anos seguintes, as reflexões filosóficas consolidaramse diante de práticas abusivas em pesquisas genéticas direcionadas para o eugenismo e, posteriormente, concentradas na criação de seres geneticamente modificados. Sempre em nome da ciência, mas, de fato por interesses econômicos. Os defensores da bioética iniciaram uma luta para criar um código capaz de inibir tais práticas. Uma tese central era de que a ciência não é mais importante que o homem. Portanto, o progresso técnico deve ser controlado por uma consciência da humanidade a fim de que as novas descobertas e suas aplicações não fiquem sujeitas a todo tipo de interesses.

Atualmente pode-se afirmar, com muita segurança, que o nome da ética é bioética. $E$ que a bioética é a ética da vida ou de todo ser vivente. $\mathrm{E}$ a pergunta desafiante, segundo Andorno, é a seguinte: Como se deve tratar a vida? ${ }^{17}$

\footnotetext{
${ }^{15}$ Atlan, Henri. Les Étincelles de Hasard - Trad. As Centelhas de Acaso. Paris: Éditions du Seuil, 1999. P.39. Trad. Para o português, O Livro do Conhecimento - As centelhas do acaso. Lisboa: Instituto Piaget.

${ }^{16}$ Revista Kosmos, 1927, Artigo: Bioética uma revisão do relacionamento ético dos homens em relação aos animais e plantas.

${ }^{17}$ Andorno, Roberto. La bioétique et la dignité de la personne. Paria: PUF, 1996, p.4.
} 


\section{EDUCAÇÃO FÍSICA}

\section{Algumas observações iniciais}

Reivindicar, sob o ponto de vista da formação acadêmica, um espaço para a ética na educação física, em princípio, não há nenhuma resistência, ainda que, atualmente, sua presença não seja obrigatória nos seus currículos. Há um decreto recente que propõe, sem obrigatoriedade, a inclusão da ética, que pode ser de diferenes formas como disciplinas, projetos, ou atividades complementares. ${ }^{18}$

Percorrendo currículos de várias universidades parece que, ainda, os debates éticos não mereceram significativos espaços. E quando se fala em ética, é confundida com deontologia. A mesma situação de quase ausência pode ser constatada nas apresentações de dissertações e teses. Certamente, há espaço para a ética, especialmente como bioética, na medida em que houver uma aproximação maior com as várias ciências biológicas e humanas.

Outro tema, muito lembrado pelos estudiosos da educação física, é o conflito existente quanto à expressão educação física, já que em países, como a França, a Holanda, a Alemanha, adotam outras designações, como cultura corporal, educação motora, educação do, para e pelo movimento, ensino do movimento. Enterpretando, uma leituraa literal, chega-se à conclusão de que a educação física deveria ser uma ação pedagógica. $\mathrm{Na}$ prática não é. Especialmente com a criação do bacharelado. E, com maior evidência, pela aproximação às práticas esportivas. Um diferencial, neste sentido pode estar surgindo com a criação do curso de Ciências do Esporte. Uma novidade no Brasil, mas já existente em outros países. Existe ainda muita confusão acerca das duas graduações, é muito comum as pessoas confundirem o curso de esporte/ciências do esporte/educação. Um fato é certo, os profissionais dos dois cursos disputam as mesmas vagas no mercado de trabalho. ${ }^{19}$

Haveria, além dessas observações, uma série de outros pontos que mereceriam ser lembrados e expressos nestas perguntas: a educação física é ciência? Qual o novo status

${ }^{18}$ Diretrizes Curriculares Nacionais para Educação das Relações Étnico-raciais e para o Ensino de História e Cultura Afro-Brasileira e Indígena (Lei $n^{\circ} 11.645$ de 10/03/2008; Resolução CNE/CP Nº1 de 17 de junho de 2004).

${ }^{19}$ Site da UNICAMP. "O curso de Ciências do Esporte nasceu junto à inovadora proposta de criação da Faculdade de Ciências Aplicadas da Unicamp, cujo projeto pedagógico contribui com a formação de profissionais de excelência frente às exigências do século XXI." 
pela sua inclusão na área da saúde? Qual o seu compromisso social? Como fundamentar a autonomia ou a legitimidade epistemológica e pedagógica? Entretanto, objetivo do tema, aqui apresentado, aponta para outro cenário, o do conteúdo que diz respeito à ética e, mais diretamente, à bioética, podendo ser resumido em dois termos: corpo e movimento.

\section{Corpo}

O objeto específico da educação física, conforme exigência para constituir-se em ciência, não foi ainda totalmente resolvido. É verdade que, no Brasil, sua história começa em 1910 com um curso provisório de educação física do exército. Na década de trinta surgiram cursos em S. Paulo e Rio de Janeira. De fato, foi na década de 1960 que a educação física entrou na Universidade. O aumento dos cursos foi rápido, especialmente, com o decreto de 1969 que instituiu a obrigatoriedade da educação física para todos os cursos universitários.

A atenção sobre o segundo termo da expressão educação física, revela, embora seja um adjetivo qualificativo, a raiz de sua identidade. Aqui, o adjetivo, física, distingue a educação física de outros tipos de educação. O mais importante, neste momento, é saber de que maneira faz parte da abrangência da semântica do conceito, a palvra física.

O termo, física, significa habitualmente o que é material, corporal, conotação que se distancia do sentido grego, Physis, (o que se manifesta). A melhor tradução seria natureza. Quando consideramos a física, como ciência, o distanciamento é ainda maior. A definição dos manuais escolares confirma: Física, "ciência que estuda as propriedades gerais da materia e estabelece as leis que dão conta dos objetos materiais". ${ }^{20}$

A compreensão de corpo, a ser desenvolvida aqui, segue outros caminhos para além da ciência física. O primeiro passo, a ser lembrado, é que se trata do corpo humano. E o corpo humano, como todos os demais corpos viventes, é um organismo vivo. O que é suficiente para ultrapassar os limites das definições e conceitos acima apresentados.

A tarefa, agora, pode começar com esta pergunta: qual a compreensão de corpo que a educação física desenvolve em todas as suas atividades? Tudo indica que será necessário, mais uma vez, descer ao porão, na metáfora de Bachelard.

Na verdade o lugar do corpo na história da humanidade, pelo menos a partir da invenção da racionalidade, sempre foi secundário e subalterno. Em nenhum momento o ser humano

\footnotetext{
${ }^{20}$ Dicionário, Petit Robert.
} 
encontrou no corpo sua identidade. Em geral os demais seres vivos, animais e vegetais foram nomeados pelas suas características físicas. Os seres humanos, no momento em que se propuseram desenhar sua identidade, procuraram um elemento oriundo de outras instâncias. Até nos mitos de origem, o corpo não é suficiente para a espécie human. Assim, na tradição bíblica, é o sopro de Javé; e a centelha de fogo de Zeus, na tradição grega. A primeira definição de homem estabelecida, talvez, a mais próxima dele, afirmava que era um ser vivo possuidor de fala (Czoon echon logon). Em seguida chegou o conceito de psíque, que era de natureza divina. O corpo, a partir deste momento, passou a ser sua moradia passageira. Para Platão, era uma prisão a que a psíque fora condenada por uma falta ignorada, e que, no corpo, não encontrava um complemento. Posteriormente, psique grega foi traduzida por alma ou espírito e incorporada à tradição bíblico-cristã. Em seguida, retomando-se a primeira definição, o Logos foi traduzido por Razão, que domina toda a cultura indo-européia.

No domínio da antropologia teológica cristã o corpo não passa de um instrumento para purificar e santificar a alma. Ele deve ser submisso, neutralizado e, até, negado. No domínio das ciências modernas, o corpo passou a ser um objeto como qualquer outro objeto de pesquisas e experimentos. Na vida diária, corpo não passa de um utensílio. É comum afirmar-se que os filósofos dedicaram-se a desenvolver a racionalidade, como única capacidade de raciocício e legitimação do verdadeiro e do falso, do bem e do mal. E o corpo teria sido entregue aos cientistas ou ao uso pessoal.

Em ambas as instâncias, filsofia e ciência, a metáfora de corpo era a de uma máquina. Descartes chegou a afirmar que o filósofo desconhecia o homem por que desconhecia a máquina. E o modelo de maquina, mais encantador, era o do relógio.

Durante o império da razão, o corpo manteve-se na situação de um servo submisso e obediente. Quando queremos entender toda a trajetória das relações razão/corpo, parte dos estudiosos nos leva para o lugar habitual, o pensamento grego, mas há uma parte considerável deles que chega até a Mesopotâmia. Para encurtar a caminhada é suficiente, conforme o tema proposto, adotar compreensões mais recentes. Horkheimer é uma boa referência. "A razão é a faculdade que possibilita o funcionamento abstrato do mecanismo do pensamento". ${ }^{21}$ Essa faculdade se tornou em sua evolução um instrumento formal, que

${ }^{21}$ Horkheimer. Max. Eclipse da Razão. Rio de Janeiro: Labor. 1976, p. 11. 
foi usado em todos os empreendimentos humanos. Assim a razão não é apenas a faculdade interior do homem, mas ela se personificou nos próprios objetos deste mundo.

A razão tornou-se racionalidade: "relação calculada entre meios e fins". Tornando-se assim o aparelho indispensável para desenvolver qualquer atividade humana. Na educação, na saúde, no trânsito, na economia, etc. Todos os empreendimentos e organizações humanos deviam ter o selo da racionalidade.

Em relação ao corpo, a conclusão se torna evidente, todo seu agir, todo seu pensar e toda sua linguagem devem pautar-se segundo o comando da razão. Numa palavra a vida humana deve ser racional.

A ressurreição do corpo começou acontecer na segunda metade do século passado, inicialmente pela revolução sexual, em seguida pela desmistificação das velhas hierarquias culturais que privilegiaram a mente sobre o corpo por força de poder regulador/regulado. ${ }^{22}$

No mundo da filosofia, a partir dos meados do século passado, surgem pensadores que se afastam da racionalidade como a essência do ser humano partindo da ideia de existência. O ser humano se caracteriza enquanto ser um ser situado e datado. Ele se faz a si mesmo pelo ato de assumir essa sua condição de um ser-no-mundo. Heidegger, certamente, é um pensador muito decisivo para as correntes existencialistas. Entretanto, o ser humano continua estritamente ligado à manifestação de consciência de si. Nesta caminhada de afastamento do racionalismo filosófico, Merleau-Ponty radicaliza afirmando que o modo de ser do homem é ser um ser corporal. Simplificando, o homem é corpo. Então o correto é dizer eu sou corpo, e, não, eu tenho corpo. Evidentemente que a compreensão de corpo, proposta por Merleau-Ponty, não é aquela da parte física do ser humano, mas a sua totalidade. Tudo o que constitui o ser humano e nele se manifesta é corporal. E corporal não é sinônimo de material, mas da totalidade de um organismo vivente.

O reconhecimento do corpo como o modo de ser do ser humano, feito por MerleauPonty, situa de maneira mais radical o homem como ser-no-mundo, ao afirmar que "o corpo próprio está no mundo como o coração no organismo: ele mantem continuamente em vida o espetáculo visível, ele o anima e o alimenta interiormente, e forma com ele um sistema" ${ }^{23}$

${ }^{22}$ Porter, Roy. História do Corpo. In Burke Peter (org.) A Escrita da História - Novas Perspectivas. Campinas SP: UNESP, 1992. P. 293.

${ }^{23}$ Merleau-Ponty. Op. Cit. P. 235. 
No domínio das ciências o conceito mecanicista do ser humano consagrado pelo médico francês Julien Offray La Mettrie, em sua obra L'Homme-Machine (O Homem-máquina), ainda que o conceito máquina permaneça, seu significado é confrontado com o conceito de organismo ou de máquina vivente. O corpo é uma organização, não só viva, mas vivente, o que quer dizer que ele desenvolve constantemente as potencialidades da vida presentes nele.

Os principais pensadores, que introduziram uma profunda revisão na compreensão do corpo humano, foram, e continuam sendo, os biólogos e os neurobiólogos. Portanto o corpo ultrapassa os limites da física e da mecânica para entrar na dinâmica da vida. A língua alemã tem um recurso linguístico muito sugestivo pela diferença entre Körper (constituição física, somática) e Leib (organismo vivo). A aproximação do corpo humano ao fenômeno da vida possibilitou o questionamento do conceito de materialidade. Admite-se, com segurança, até com auxílio da ciência (um caso, os neutrinos), que se pode pensar em diferentes materialidades. Husserl afirmou: "A corporeização das almas é alguma coisa que cada um somente experimenta de maneira original nele mesmo."24

Portanto a vida passou a ser o ponto de partida para construir o novo perfil do corpo humano. Entre os muitos estudiosos do assunto, será necessário optar por alguns com base no critério de serem, entre nós, mais referidos por estudiosos do tema.

Antônio Damásio, neurobiólogo e chefe do departamento de neurobiologia da Universidade de lowa, merece ser lembrado ao declarar que "Qualquer que seja a questão que possamos levantar sobre quem somos e por que somos como somos, uma coisa é certa: somos organismos vivos complexos, com um corpo propriamente dito ("corpo", para abreviar) e com um sistema nervoso (cérebro, para abreviar)." 25 Para Damásio todas as partes do organismo vivo interagem de maneira integrada através do cérebro.

Humberto Maturana e Francisco Varela, provavelmente, sejam os mais acessíveis para entender a questão dos seres vivos. Isto por que a grande questão que norteou as pesquisas de ambos é esta pergunta: "o que é a vida?". Na busca de respostas formularam outra pergunta, menos metafísica e mais voltada para a constituição dos sistemas vivos: "o que é próprio dos sistemas vivos desde sua origem, e permanece invariante durante as ${ }^{24}$ Husserl. E. Op. Cit. P. 244.

${ }^{25}$ Damásio. Antônio. O Erro de Descartes - Emoção, Razão e Cérebro humano. São Paulo: Cia. das Letras, 1996. P. 112. 
suas sucessivas gerações"? A resposta foi encontrada na criação do termo "autopoiese", que significa auto-criação, auto-organização, auto-desenvolvimento. Portanto, sistemas autopoiéticos são sistemas auto-referidos, nos quais seu operar somente faz sentido em relação a si mesmos ${ }^{26}$ Com base nestas constatações pode-se concluir que tanto a vida, em geral, quanto o corpo humano, em particular, não tem sentido fora deles, mas neles mesmos. Quando atribuímos à vida ou ao corpo um sentido estabelecido de fora, isto faz parte de uma cultura. Por isso o conceito de homem-máquina de La-Metrie é uma criação cultural, tanto quanto o corpo pecador do Cristianismo medieval.

Para completar a descrição das "máquinas auopoiéticas" é significativo lembrar três características apontadas por Maturana:

a) Autonomia - "As máquinas autopoéticas são autônomas; quer dizer subordinam todas as suas mudanças à conservação de sua própria organização".

b) Individualidade - "As máquinas autopoéticas possuem individualidade; isto é, por meio da manutenção invariável de sua organização conservam ativamente uma identidade que não depende de suas interações com o observador".

c) Unidade - "As máquinas autopoéticas são definidas como unidade por sua organização autopoiética: suas operações estabelecem seus próprios limites no processo de autopoiese". ${ }^{27}$

\section{Movimento}

Se a aceitação e a aplicação do novo perfil de corpo - um corpo vivo ou vivente - estão ainda longe de influenciar as práticas e os currículos da educação física atual, não menos complexa é a inclusão de uma nova compreensão de movimento, baseada neste perfil de corpo vivente. Um corpo, organismo vivo, rompe com os limites do movimento desenhados pelas leis físicas e mecânicas. A complexidade aumenta quando se percebe que não se trata apenas de mudanças no interior da educação física, mas de consequências inimagináveis na vivência do movimento e nas aplicações de exercícios nas academias e, de maneira mais significativa, nas práticas esportivas.

\footnotetext{
${ }^{26}$ Maturana, H. Varela F. De Máquinas e Seres Vivos - Autopoiese: A Organização do Vivo. Porto Alegre: Artes Médicas, 1997. P. 2-17.

${ }^{27}$ Maturana, H; Varela, F. Op. Cit. P. 73.
} 
A questão do movimento se instalou desde o momento em que surgiu o projeto de estabelecer um conhecimento como representação da realidade. Para isto julgouse necessário fixar a realidade num tempo. As essências são estáveis por detrás das modificações na linha do tempo. "Para a mente humana, escreveu Bergson, a imobilidade Ihe pareceu mais clara que a mobilidade. Foi assim que o problema do movimento foi levantado desde a alta antiguidade". ${ }^{28}$ As ciências modernas mantiveram o privilégio da imobilidade do real.

Torna-se desnecessário, neste momento, descrever o movimento humano desenvolvido segundo as ciências físicas, a mecânica e as tecnologias. Repetindo e resumindo, o corpo é uma usina de energia que pode gerar movimentos e, por sua vez, estes movimentos não têm valor em si mesmos, mas nos produtos alcançados. E, para completar, não é qualquer produto e sim o de índices de perfórmance. Por exemplo, nos esportes, especialmente nos de alto rendimento, não é o corpo que é glorificado, mas o trofeu obtido, com ênfase o de primeiro lugar. Em caso de recorde ou de sua superação do mesmo, é a suprema glorificação. Nem convém lembrar os supostos "esportes" UFC e MMC

A revisão da compreensão do movimento humano físico/mecânico em favor da compreensão do movimento vital e existêncial, como já foi lembrado, começa a partir das ciências que concentram o estudo naquilo que Maturana designou como "o operar do fenômeno biológico". ${ }^{29} \mathrm{O}$ movimento humano, essencialmente humano se confunde com o movimento do operar do DNA. Neste sentido, segundo Maturana/Varela, o ser vivo é uma dinâmica molecular, não um conjunto de moléculas e, mais, ele (ser vivo) não usa essa dinâmica, ele é essa dinâmica molecular. ${ }^{30}$ Esse movimento da dinâmica molecular nunca esteve ao alcance do olhar da Física. O campo de sua visão limitou-se a estudar o movimento dos corpos, sem distinção entre as máquinas autopoiéticas e as máquinas alopoiéticas. Essas últimas dependem da ação de seu organizador e seu funcionamento é algo diferente delas mesmas.

O movimento vital do corpo humano é o responsável, do início ao fim, pelo desenvolvimento e pela manutenção de sua existência. Deste modo a vida para o ser

\footnotetext{
${ }^{28}$ Bergson, Henri La Pensar et le mouvent. Paris: PUF. 35a . 1960, p.205.

${ }^{29}$ Maturana, Humberto, Varela, Francisco. De Máquinas e Seres Vivos; Autopoiese - A Organização do vivo. Porto Alegre; Artes Médicas, 1997. P. 12

${ }^{30}$ Maturana/Varela. op. Cit. P.16.
} 
humano é viver humanamente. Assim como para a mosca é viver como mosca. Numa palavra o movimento da vida se chama viver.

O desafio, provocado por essa revisão da compreensão do movimento humano, consiste em transferir a dinâmica molecular que sustenta a organização autopoiética, para a esfera dos movimentos nas relações com o mundo. Mundo entendido como o meio ambiente e como interações sócio-culturais. O conceito de Lebenswelt (mundo da vida) de Husserl expressa de maneira clara e simples as relações organismovivo/mundo como uma unidade integrada.

Num primeiro momento, parece fácil e simples, seria apenas ultrapassar a comprensão do movimento corporal humano no mesmo nível do movimento de qualquer corpo, consolidado pelas leis da físicia e da mecânica. Esta ultrapassagem se daria pela demonstração de que os organismos vivos possuem uma dinâmica com outra lógica.

O segundo momento é mais complexo por que exige que se vinculem os movimentos, como se diz habitualmente, exteriores aos movimentos interiores dos organismos vivos. Inicialmente é preciso sublinhar que a origem de todo movimento se origina da vida. Portanto, não tem sentido, falar entre exterior e interior. Apenas uns são mais visíveis outros menos. Não se pode esquecer que, desde Heidegger, o ser humano é um ser mundano, isto é, ele é mundo. O mundo é um componente da existência, o que está explícito no Dasein. Portanto qualquer movimento, não importa a adjetivação, é uma manifestação da dinâmica organizacional autopoiética dos seres viventes, porque, repetindo a citação de Maturana, "seu operar somente faz sentido em relação a si mesmos".

Nesta compreensão de movimento fica claro que ele tem um valor em si mesmo, não como força produtiva que transfere o valor para o produto.

Um conceito que está trazendo uma contribuição importante para a revisão do movimento humano é o de "se-movimentar", ainda pouco difundido e, talvez, menos ainda compreendido, mas que, certamente, está revolucionando, ainda que lentamente, a mentalidade pedagógica dos profissionais da educação física. O maior mérito da divulgação do "se-movimentar" deve ser atribuído, incontestavelmente, ao Prof. Elenor Kunz pelos seus trabalhos relacionados com Trebels e Tamboer. 
A importância e o significado da idéia do "se-movimentar" mereceriam maiores aprofundamentos, entretanto, um ponto deve ser sublinhado, o que ele, no meu entender, é um complemento das posições de Maturana e Varela, já relatadas anteriormente. O homem "se-movimentar" revela que quem se movimenta e o movimento constituem uma unidade. Segundo Merleau-Ponty é impossível separar o sentido do gesto do braço com o próprio braço. Alguns gêneros de dança, em especial o flamenco e o samba, são apontados como exemples perfeitos desta fusão entre dançarino e dança. Um exemplo oposto seriam os desfiles de modelos.

No contexto do "se-movimentar", não há, certamente, nenhum impedimento de acrascentar a iniciativa de Peter Heinj propondo a substituição da expressão Educação Física por Ensino do Movimento Humana (EMH) em favor do "se-movimentar." A aproximação entre as duas propostas pode ser resumida nestas palavras do próprio Peter: “considero fundamental caracterizar o Ser Humano como 'homo se movens', um ser que se movimenta. Por isso a Educação Física não pode partir de exercícios físicos sob comando, mas do se-movimentar humano, também não pode almejar apenas rendimentos físicos mas a autonomia criativa e autoregulativa do ser humano, essa deve ser a base educacional da Educação Física". ${ }^{31}$

Por fim, à idéia de ensino, não educação, do movimento humano, é possível acrescentar a idéia de inventar o ofício de aprender, apresentada por Hélène Trocmé-Fabre. O ensino não seria transmitir conteúdos, mas ensinar aprender. Junto com os termos como aprendência e universidade aprendente, Hélène substitui o celébre "cogito ergo sum" de Descartes, por "J'apprends donc je suis" (Aprendo logo existo). ${ }^{32}$ Sem dúvida o ser humano é um ser que aprende, mas há um elemento diferencial com os outros seres vivos que aprendem, o homem cria seus modelos de aprender. E, o que é mais original, ele pode renovar seu aprender.

\section{CONSTRUÇÃO DE CONHECIMENTOS}

A preocupação humana de conhecer está entre as raízes da evolução da espécie. Outros seres vivos também possuem a faculdadade de conhecer. O que diferencia o conhecer

${ }^{31}$ Heinj, Peter. Educação Física. Tradução em andamento de Elenor Kunz. P. 7.

32 Trocmé-Fabre, Hélène . Reinventar o Ofício de Aprender. São Paulo: TRION, 2010. P.18. 
humano dos demais seres vivos é sua capacidade de criar modelos ou paradigmas de conhecimentos. E não só de criar, mas de renovar, modificar e transmitir. Foi assim que o homem se tornou um ser cultura,I e definiu-se a oposição entre Natureza e Cultura.

Os primeiros modelos de conhecimentos foram formados pelos mitos de origem, cuja base teórica está na dinâmica do sagrado. Posteriormente, identificada a insuficiência do sagrado, embora não eliminado, foi elaborada uma lógica racional, baseada em princípios mentais. O mais decisivo é o princípio de causalidade que domina as ciências até hoje. $\mathrm{O}$ maior resultado é a constituição do saber conceitual. Uma vez constituído o conceito, aceito como a representação mental do real ou como espelho fiel da natureza, o conhecimento pode ser adquirido através do discurso conceitual sem o contato imediato com a natureza.

Neste cenário, para simplificar, surgiram as filosofias racionalistas e as ciências modernas. As filosofias racionalistas desenvolveram a metafísica como fundamento último de todo conhecimento. $\mathrm{E}$ as ciências empíricas estabeleceram o critério de verdade na objetividade do conhecimento, expresso em duas palavras: conhecimento científico. Nesta dupla racionalidade, a científica e a filosófica, se estabeleceu, como exigências indispensáveis, a enfretamento sujeito/objeto, a neutralidade do observador e a exclusão da subjetividade.

Atualmente, falar em crise das ciências não é novidade. As críticas são cada vez mais comuns e profundas, desde a proclamada legitimidade do paradigma científico adotado insdistintamente, até as desastrosas consequências para toda a natureza, especificamente, a sobreviência da vida humana e do planeta Terra. Husserl, já na primeira metade do século vinte reclamava dizendo que "essa ciência não tem nada a nos dizer. As questões que ela exclui por princícpio são precisamente as questões mais ardentes da nossa época para uma humanidade abandonada ás reviravoltas do destino"33

As origens e os mistérios da natureza, que provocavam a humanidade a procurar explicações pela via do conhecimento, agora são substituídos pelos graves problemas oriundos do domínio deste conhecimento e de sua irmã siamesa, a tecnologia, que afligem a humanidade. Guerras mortíferas, destruição da natureza, poluição, desigualdades sociais, doenças epidêmicas, opressões de toda ordem, miséria, fome, injustiças, intolerências, etc.

${ }^{33}$ Husserl.E. Op. Cit. P. 10 
Essa constatação por si só não resolve os problemas. É preciso apelar para um gesto mais propositivo. A resposta poderia ser: construir uma nova cientificidade.

O primeiro sinal para a busca deste sonho estaria em contrapor à pretensa ortodoxia cognitivista da comunidade científica outros parâmetros ou paradigmas de conhecimento. Muitos são os pensadores que comungam desta idéia, Varela, entre eles, abre o caminho demonstrando que a ciência é apenas uma das estruturas imaginárias provenientes das práticas sociais, que vigora numa época da história da humanidade. ${ }^{34}$ Antes de Varela, Alexandre Koyré e outros filósofos e historiadores das ciências mostraram que a imaginação científica se transforma radicalmente de uma época para outra. ${ }^{35}$ Gérard Fourez é ainda mais radical ao afirmar que "a ciência varia de acordo com o grupo social". A justificativa, por ele apresentada, é a seguinte: "A ciência moderna, em particular, liga-se à representação do mundo própria da burguesia, que se sente exterior ao mundo, ao mesmo tempo em que tenta explorá-lo e dominá-lo. (...) A ciência moderna surge como uma produção cultural de uma civilização particular, que pertence ao sistemaa aristocrático feudal" . ${ }^{36}$

A possibilidade de uma outra cientificidade pode estar na adoção da vida como ponto de partida para superar a simplificção da lógica causalística e traçar uma logicidade pelo pardigma da complexificação. A vida não será mais um simples objeto das ciências, mas fonte inspiradora de cientificidade. As ciências empíricas não são negadas, mas fica evidente que os seres vivos precisam ser tratados com outra lógica, a lógica da vida, cuja dinâmica é expressa pelo conceito de complexidade. E o complexo não pode ser reduzido à simplicidade, mas deve ser mantido como complexo. Para que isto seja operacionável devese substituir a explicação e a análise das ciências pela interpretação e pela compreensão da hermenêtica. Portanto, não se trata de dizer o que a vida é, mas de descrever o processo de sua auto-organização que se manifesta em cada organismo vivo.

Seguindo a orientação do tema proposto, é preciso focar a atenção sobre o ser humano enquanto ser corporal. Para não esquecer, aqui, o sentido de corporal abrange a totalidade do ser humano, sem excluir nenhuma dimensão.

\footnotetext{
${ }^{34}$ Varela Op. Cit. P. 10-11

${ }^{35}$ Koyré, Alexandre, 1892-1964. Filósofo e historiador das ciências, aluno de Husserl, escreveu: Du monde clos à l'univers infini.( Do mundo fechado ao universo infinito). Paris: Gallimard, 1957.

${ }^{36}$ Fourez, Gérard. A Construção das Ciências - Introdução à Filosofiaa e à Ética das ciências. Campinas SP: UNESP. P. 191.
} 
Entre outras maneiras de tentar compreender a dinâmica do vivente, provavelmente, uma das mais significativas seria da "aprendência", assim definida pela autora: "A aprendência tem, antes de tudo, um estatuto de ato existencial, em plena coerência com as leis da vida, Aprender é obedecer a uma lógica plural; de regulação, de adaptação e de evolução. (...) O estatuto da aprendência é duplo: a simultaneamente causa e consequência da transformação gerada e constatada". ${ }^{37}$ A simultaneidade de causa e consequência é uma caraceterística da auto-organização e da autopoiése, fator fundamental da complexidade. (Uma pausa: "A incontornável complexidade - (do latim 'complexus' que significa 'tecer juntos') - pode ser considerada como a resultante de um processo de complexificação que, segundo certas teorias, serve de base dinâmica da evolução do Universo e do vivente. Mas, certamente, a complexificação não é o único processo de evolução e a evolução não é sinônimo de progresso". ${ }^{38}$

A escuta do meio ambiente faz parte da "aprendência", mas para conseguir essa escuta é fundamental vencer as imensas barreiras de certezas que nos envolvem e sobreviver nos espaços dominados pelas tecnologias. Vencidos esses obstáculos será possível, afirma Hélène, iniciar uma leitura do Universo e da Vida, sob um novo enfoque. O novo enfoque começa por seguir as lições do ser vivo que constam de seis pontos e constituem o seu viver quotidiano:

a) A diversificação que resulta do complexificador.

b) A complementaridade está presente no ADN.

c) A troca e a cooperação, características das relações entre células. Neste sentido Maturana defende que a natureza não é competitiva, mas coloborativa.

d) A conexão é o processo de religar todas as regiões do organismo.

e) A auto-organização é o termo central que determina o processo de alcançar o pleno desenvolvimento do organismo, sem a necessidade de intervenções externas, pela capacidade que tem a estrutura vivente de se regular e modificar seus próprios mecanismos.

f) A seletividade é a capacidade que o organismo vivo tem de fazer escolhas. ${ }^{39}$

A vida, enquanto tal, não existe. Existem seres vivos. Assim como o Homem, enquanto tal, não existe. Existem seres humanos. Portanto será pela leitura do organismo vivo que

\footnotetext{
37 Trocmé-Fabre. H. Op. Cit. P. 30.

38 Trocmé-Fabre, H. Op. Cit p.58.

39 Trocmé-Fabre. H. Op. Cit. P. 42-62.
} 
conhecemos o operar da vida. A tarefa começa pelo reconhecimento de que o corpo que somos é o livro que cada um precisa ler. Infelizmente não somos nem habituados nem habilitados, para ler o livro que somos, não que temos. Essa leitura nos constitui leitores e lidos. Da mesma maneira que simultaneamente nos tocamos e somos tocados. Esse conhecimento não é ensinado, mas vivido, experienciado por cada um, o que o torna inalienável.

Henri Atlan, em Les Éticelles de Hasard (As Centelhas de Acaso), escreveu: "Ninguém sabe o que pode o nosso corpo. É, pois, em termos de conhecimento, ou antes, de ignorância, que é formulada a questão daquilo que o corpo faz. (...) Conhecemos do nosso corpo, mas não sabemos como o nosso corpo conhece (...) E sabemos como sabemos, enquanto não conhecermos o conhecimento que o nosso corpo tem. A nossa própria identidade é indissociável do nosso corpo: nós somos o nosso corpo". ${ }^{40}$

As seis lições do ser vivo, acima apresentadas, constituem o caminho do encontro com o corpo que somos. Um encontro do corpo com o corpo. O corpo das ciências não coincide com o corpo vivente.

Neste cenário, onde a vida se manifesta, surge a possibilidade de assumir o saber e o fazer do corpo para garantir a plenitude de seu desenvolvimento. É aqui, também, que se póde encontrar os princípios da eticidade que as ciências não conseguem encontrar.

A ética não está nem na natureza nem na vida, estas podem ser apenas os presupostos estabelecidos para fundar a eticidade. É o ser humano quem define os pressupostos. No momento, a vida está sendo uma opção preferencial confirmada pela aceitação da bioética como sendo, hoje, o nome da ética.

\section{PROFISSIONALIZAÇÃO E PROFISSIONALISMO}

Profissionalismo e profissionalização são dois conceitos empregados, à vezes, como sinônimos, entretanto, não dizem a mesma coisa. Profissionalização é o processo de capacitação para exercer uma profissão. Profissionalismo é a qualidade de se comportar conforme as normas da profissão. Os tratados sobre profissões definem profissionalismo como "ação, procedimento, qualidade ou característica do bom profissional, daquele que

${ }^{40}$ Atlan, H. Les Éticelless de Hasard. P. 93 
é competente, capaz, proficiente, responsável, sério, pontual, ético etc. em sua profissão. Profissionalização é "tornar (alguém ou a si próprio) profissional. Por exemplo, a federação profissionalizou os árbitros. Muita gente busca as oficinas para se profissionalizar".

Tanto profissionalização quanto profissionalismo são derivados de profissão. O ponto comum consiste em saber o que constitui uma profissão. Sua constituição pode ser concentrada em quatro elementos: a) uma atividade específica vinculada a organizações sociais ou a sistemas produtivos; b) um conjunto de conhecimentos e técnicas que habilite a exercer responsavelmente tal atividade; c) uma demanda social exigindo a prestação de tal serviço, geralmente, denominado mercado de trabalho; d) reconhecimento oficial como profissão. Por exemplo, o reconhecimento dos egressos dos cursos de Educação Física como profissionais, que é recente. ${ }^{41}$

Nos limites do tema proposto não está a questão dos curriculos acadêmicos, que definem o conjunto de conhecimentos exigidos, mas apenas a presença dada à ética ou à bioética.

\section{Fonte de inspiração}

Seguindo a linha de raciocínio desde o início deste trabalho a conclusão é clara: a fonte de inspiração é a vida, não num sentido genérico, mas a vida que vivifica todo organismo vivente, no caso presente, o corpo humano. A vida seria a primeira, talvez, a única fonte capaz de dar as diretrizes originais de estabelecer uma eticidade, compreensível universalmente e que não exclui ninguém. É a vida que conduz a autopoiese de cada corporeidade individual. Repetindo mais uma vez, sou ou somos corpo, portanto a éticidade, cujo nome mais correto seria a bioeticidade, consiste em respeitar e acompanhar o processo evolutivo do sistema auto-referido corporal. Novamente, corporal não é um termo reducionista, mas a unidade plena da viver de uma pessoa. É a vida que fundamenta e ordena o convívio social em todas as suas organizações.

Aeducação física, atualmente, está presente em três áreas fundamentais da vida humana, num momento decisivo em que se proclama a libertação do corpo. Uma responsabilidade sem precedentes.

\footnotetext{
${ }^{41}$ Brasil. Lei $n^{\circ} .9 .696$ de sentembro de 1998. Dispõe sobre a Regulamentação da Profissão de Educação Física e cria os respectivos Concelho Federal e Conselhos Regionais de Educação Física. Diário Oficial da União, Brasilia DF, 2 de setembro. 1998b.
} 
A) Educação. A educação física, como dizem as palavras, foi entendida quase exclusivamente como uma ação pedagógica, embora fosse uma pedagogia não centrada no corpo, mas atrelada ao desenvolvimento intelectual. Os próprios docentes da educação fisica eram vistos como sendo de outra categoria. Além disso, nos boletins, era registrada, geralmente, como Ginástica. O corpo era tratado como a parte física da pessoa, que devia estar a serviço do bom desempenho da inteligência. Uma frase, frequentemente repetida, dizia que se matriculava a inteligência, não o corpo. As atividades físicas propostas tinham o caráter de recreação e de disciplina. Fazim um contraponto ao sedentarismo e ao imobilismo das salas de aula.

Com a nova compreensão de corpo e de movimento (se-movimentar), a educação física recebeu uma tarefa mais comprometedora, a de resgatar a dignidade e a identidade corporal do ser humano. A ação pedagógica pela nova compreensão de corpo, que teria sido inaugurada pela anuciada ressurreição do corpo de Roy Porter (já referido anteriormente), de fato, aconteceria pela aceitação, respeito e vivência do próprio corpo. A sua consolidação somente se daria pela alfabetização corporal. A alfatização corporal consiste na leitura da linguagem corporal. O corpo é falante. ${ }^{42}$ Sua fala, não é vocalizada, mas de mensagens múltiplas. As mais perceptíveis são as dores, são os sofrimentos, a fome, o frio, o calor, o prazer, a alegria, as emoções, os sentimentos, etc. Esses, geralmente, podem ser percebidos externamente. Mas há mensagens que são vividas e sentidas apenas por cada um. Para interpretar tais mensagens é preciso uma escuta especial que somente acontece pela albetização autodidata.

Educar o corpo não é impor-Ihe disciplinas, mas aprender escutá-lo. Esta é a maior dificuldade como lembra (e repetindo) Henri Atlan: "E não sabemos como sabemos, enquanto não conecermos o conhecimento que o nosso corpo tem".

Um aspecto que a educação física (ação pedagógica) não pode esquecer é a questão da decantada liberação do corpo. Jean-Marie Brohm trata, em várias obras, a suposta civilização do corpo sob o aspecto de sublimação e dessublimação repressiva. ${ }^{43}$ Apenas como referência sugestiva, Michel Foucault é sempre lembrado como denunciador da

\footnotetext{
${ }^{42}$ Merleau-Ponty, em Phénoménologie de la Perception, dedicou um longo capítulo ao tema: Le corps comme expression et la parole. (O corpo como expressão e a fala) p. 180-232.

${ }^{43}$ Brohm, Jean-Marie. Rev. Partisans: Sport, culture et répression, La civilisation du corps: Siblimation et dessublimasation répressie. P. 59-85.
} 
pedagogia dos "corpos dóceis", praticada em escolas, quarteis e prisões ${ }^{44}$. Georges Vigarello é outro estidioso da história pedagogia que revela o tratamento dado ao corpo: "O corpo é o primeiro lugar onde a mão do adulto marca a criança, ele é o primeiro espaço onde se impõem os limites sociais e osicológicos dados à sua conduta, ele é o emblema onde a cultura vem inscrever seus signos como sendo brasões". ${ }^{45}$

B) Esportes. A segunda área de atuação da educação física abrange as inumeráveis práticas esportivas, certamente a mais abrangente e, consequentemente, a muito maais complexa.

Um fator a ser considerado é que o esporte moderno foi incorporado recetemente à educação física. Para alguns o esporte, em especial o moderno, teria preenchido o vazio do conteúdo programático da educação física. Sob esta ótica pode-se dizer que teria sido o esporte que adotou a educação física como cobertura acadêmica. Esta pode ser apenas uma questão acadêmica. Há outros fatores mais importantes sobre a questão de critérios.

A quem compete responder, entre outras, às seguintes perguntas:

1. O esporte é uma atividade específica, distinta das outras atividades humanas, ou é o sentido dado à uma atividade que a transforma em esporte?

2. O esporte é uma atividade diferenciada do mundo do trabalho ou é parte dele?

3. O esporte está definitivamente incluído no mercado de trabalho e no sitema produtivo econômico?

4. O esporte valoriza as possilidades e limites do corpo?

5. Os eventos esportivos promovem a integração dos povos?

As respostas são claras e transparentes, basta fazer uma interpretação das práticas e eventos esportivos amplamente divulgados pelos meios de comunicação, portanto ao alcance de todos.

C) Saúde. A nova área de atuação da educação física, e com todo direito, é a da saúde. Talvez, a saúde seja a área mais concernente à educação física. Óbvio se a educação física tiver como centro de sua atuação a corpoeidade humana, em sua constituição como corpo vivente, e suas manifestações no se-movimentar. Tudo na perspectiva de prevenção.

\footnotetext{
${ }^{44}$ Foucaualt, Michel. Surveiller et Punir. Paris: Gallimard, 1975. E Microfísica do Poder. Rio de Janeiro; Edições Graal, 1979.

${ }^{45}$ Vigarello, Georges. Le corps redressé - Histoire d'un pouvoir pédagique. Paris: Delarge, éditeur. 1978. P. 9.
} 
Se a educação cognitiva ou mental tem como centro o desenvelvimento das faculdades mentais, a educação física tem como centro o bom desenvolvimento do operar corporal. As duas formas de educação cognitiva e física formam um todo integrado tendo o cérebro como seu ponto de origem e de comando. Na primeira, o raciocínio é a dinâmica fundamental, na segunda, é o movimento. O equilibrio entre ambas é a garantia da saúde.

Crenças que geram dúvidas. Pensar a articulação das três áreas parece não ser uma tarefa difícil a partir de duas afirmações: o esporte é saúde, o esporte é educacional. Essas afirmações geraram crenças inânimes, ou quase. Mas há algumas questões a serem consideradas a parter dos fatos. Por exemplo, se o esporte é saúde, como explicar tantas lesões? Como entender o apelo ao uso de drogas, provocando o controle antidoping? Se for saúde, porque os clubes precisam manter o departamento médico e os grandes eventos precisam incluir um enorme aparato de assistência médica? E a medicinam, dita esportiva, foi desenvolvida para sanar os malefícios das práticas esportivas, ou para prevenir?

E o que dizer do esporte educacional? O esporte de competição é fator educativo? Que tipo de educação? Mas se Maturana tiver razão ao afirmar que "a competição sadia não existe. A competição é um fenômeno cultural humano, e não biológico. Como fenômeno cultural, a competição se constitui na negação do outro" . ${ }^{46}$ O esporte desenvolve o operar corporal biológico ou impõe o desenvovimento do movimento mecânico?.

Por fim, como harmonizar com a educação e a saúde as várias atividades englobadas sob estas duas síglas UFC e MMA? Elas pertencem, atualmente, ao mundo dos esportes. Entretanto, as rinhas de galos são condenadas.

Como fica a questão ética? E a bioética, como a ética da vida?

\section{PERSPECTIVAS}

A partir do que foi apresentado chegou a hora de traçar pespectivas para pensar a construção de uma eticidade em nome da Bioética. Não é Preciso muita sabedoria para saber que ética, conhecimento e profissão são instituições dinâmicas. Não estáticas, como muitos pensam. Elas são criadas e recriadas constantemente para acompanhar o mundo e a sociedade em constantes transformações. A história das civilizações humanas monstram a presença das mudanças de saberes, de atividades e de valores. Diante destas

${ }^{46}$ Maturana, H. Emoções e Linguagem na Educação e na Política. Belo horizonte: Ed. UFMG,.2009. p. 13. 
circunstâncias, Henri Bergson, já no início do século passado, alertava que o "pensamento analítico (próprio das ciências) opera sobre o imóvel, enquanto a intuição opera sobre o móvel". ${ }^{47}$ Segundo ele, basta uma simples observação para perceber que os avanços mais significativos dos saberes humanos dependeram da intuição ou, como Atlan prefere chamar, das centelhas de acaso.

Em relação à fixação dos pressupostos da eticidade universal, percebe-se que há mais frustrações do que soluções. A oposição entre Thomas Hobbes e Jean-Jacques Rousseau não foi superado. Hobbes disse que o homem em estado de natureza é lobo do homem (Homo hominis lupus). Enquanto Rousseau afirmou que a sociedade corrompe o bom selvagem.

Duas anedotas, narradas por François Jacob, refletem bem o dilema. A primeira, muito conhecida, é a do Escorpião e a Rã. O escorpião, querendo atravessar o rio, solicita à rã que o transporte. Ela retruca: eu não sou louca, para você me picar. Com a promessa de não ser picada e com bom pagamento, a rã concorda. No meio da travessia, o escorpião pica a rã. Esta pergunta: porque fez isto? Resposta: porque faz parte da minha natureza. E os dois afundam. A segunda é menos conhecida. Um jovem etnólogo estuda uma população africana que não se sabe se deve ser classificada com os grandes símios ou com os seres humanos. Para decidir o etnólogo se casa com uma fêmea do grupo. Nasce um filhote. Ele o mata e deve comparecer, em Londres, diante de uma corte de justiça para declarar se se tratava de um homicídio ou de uma partida de caça. A senteça do tribunal foi: "é a lei que decidirá sobre a natureza". 48

Esse mesmo conflito pode ser mais claro nesta narrativa de Dennis Overbye. Conta, Overbye, que Allan Sandage, filho de um professor da Universidade de Miami e de uma mulher filipina, sofria a tensão de duas tendências, a terrena e a extraterrena, que se chocavam em sua formação e em sua natureza. Sandage descrevia-se como uma criança religiosa. Ao mesmo tempo, suas primeiras impressões da natureza foram carregadas de espanto e fascínio. A sua fase de formação foi desenvolvida em um ambiente intelectual. Tempos depois,voltou à tona o antigo fascínio e encanto, que julgava sepultados para

\footnotetext{
${ }^{47}$ Berson, Henri. La Pénsée et le Mouvant. Paris: PUF. 1931 35ª. 1960. P. 202.

48 Jacob, François. La souris, la mouche et l'homme. (Trad. O rato, a mosca eo homem) Paris: Ed. Odile Jacob, 1997.p. 90/91
} 
sempre. E relata um fato: "Papai, papai, olhe, olhe - uma flor! Não é fantástica?" E o menino sentia-se solitário em sua admiração ${ }^{49}$.

Sem negar os esforços passados, ao contrário, reforçando e reconhecendo as contribuições para criação de bioética foi possível adotar outro modo de ver, de perceber, de compreender e de descrever o universo a partir do fenômeno mais "miraculoso" acontecido, a Vida. A esse respeito Jacque Monod escreveu: "Atualmente não temos direito de afirmar, nem de negar que a vida tenha aparecido uma única vez sôbre a Terra, e que, em consequência, antes que ela fosse, suas chances eram quase nulas. (...) O universo não estava grávido da vida, nem da bioesfera, nem do homem. Nosso número saiu do jôgo de Monte Carlo". ${ }^{50}$ Para Jacques Monod o surgimento da vida requereu o concurso de tantas coincidências que levou muitos milhões de anos para acontecer, e que uma nova oportunidade se avizinha do zero.

A percepção do processo evolutivo e, em especial, do operar da vida somente pode darse pela acuidade de escutar, de sentir ou de ver. Os exemplos, mais uma vez, oferecem a melhor compreensão. A começar pelas palavras do fotógrafo francês Henri-Cartier Bresson: "Se você vê, você tem a imagem, seja com uma digital, uma analógica ou uma lata de leite ninho furada. (...) E a capacidade de ver o momento decisivo exige presença e olhar intuitivo". 51

Outro exemplo é lembrado por Konrad Lorenz quando lamenta o senguinte: "Um dos maiores prejuizos que o pensamento cientificista trouxe à humanidade consiste em que na atual instrução dos médicos o desenvolvimento do 'olhar clínico' pode receber pouco peso; é uma esperança fátua e ilusória a de que esta característica de nossa percepção possa ser substituída por grandes quantidades de dados e por seu processamento através de computadores". ${ }^{52}$

Outros exemplos podem ser encontrados nas atitudes como as descritas poeticamente por Cora Coralina:

\footnotetext{
${ }^{49}$ Overbye, Dennis. Corações Solitários do Cosmos. São Paulo: Mercuryo, 1993. P. 17.

${ }^{50}$ Monod, Jacques O Acaso e a Necessidade. Petrópolis, RJ: Ed. Vozes, 1976. P. 163/4.

${ }^{51}$ Revista, Carta Capital. 11.08. 2004.

52 Lorenz, Konrad. Der Abbau des Menschlichen. Verlang München.1983. Trad. A Demolição do Homem (deveria ser do humano). Ed. Brasiliense p. 194.
} 
"Muitas vezes basta saber:

Colo que acolhe

Braço que envolve,

Palavra que conforta"

Em nome de Cora coralina, de Konrad Lorenz e De Henri-Cartier Bresson pode-se afirmar que a ética se funda e se alimenta de sensibilidade, de emoção. Nesta perspectiva Michel Maffesoli fala em ética da estética. "Estética no seu sentido etimológico, isto é, o fato de que eu vou experimentar emoções com os outros". ${ }^{53}$

A proposta da Ética da Estética, sem dúvida nenhuma, pode-se afirmar que encontra eco na idéia de socialidade de Humberto Maturana. Esse elo do pensamento de Maturana com a ética da estética está nestas afirmações: "não é a razão o que nos leva à ação, mas a emoção. E a emoção fundamental que torna possível a história da hominização é o amor - (...) - por isso digo que o amor é a emoção que funda o social". As relações sociais e a vivência de si mesmo, insiste Maturana, não partem do racional e sim do emocional. A origem de todas as nossas decisões, em qualquer esfera, está na sensibilidade, isto é, na capacidade de viver emoções, inclusive quando se opta pela racionalidade. Proclamar o racional como a última instância da identidade humana, não é uma escolha racional, mas emocional. Os critérios do racional classificam e, por este procedimento, é possível diferenciar e excluir. A sensibilidade do amor não pode, em sua essência, produzir exclusões, porque o "amor é constitutivo da vida humana, e não é nada especial". Nas obras de Maturana há uma insistência repetitiva sobre o emocional e sua manifestação primordial, o amor, como fundamentos da vida pessoal e da convivência social. Para documentar essa observação sobre o esforço insistente de redefinir o espaço do emocional na vida individual e nas relações interindividuais, nada mais justo do que recorrer a suas palavras: "Repito: sem aceitação e respeito por si mesmo não se pode aceitar e respeitar o outro, sem aceitar o outro como legítimo outro na convivência, não há fenômeno social". ${ }^{54}$

As últimas palavras, pouco acadêmicas e nada científicas, podem ser as de Antoine De Saint Exupéry: "Adeus, disse a raposa. Eis o meu segredo. É muito simples: só se vê bem com o coração. O essencial é invisível para os olhos". ${ }^{55}$

\footnotetext{
${ }^{53}$ Maffesoli, Michel.A Comunicação Pós-Moderna como Cultura, In Textos Comunicação e Pós-Modernidade. NN. 28 Salvador: Bahia. 1992. P. 8.

${ }^{54}$ Maturana, Humberto. Emoções e Linguagem na Educação e na Política. P.23/4

${ }^{55}$ Saint Exupéry, Antoine de. O Pequeno Príncipe. Rio de Janeiro: Agir. 1964, p. 74.
} 


\section{REFERÊNCIAS BIBLIOGRÁFICAS}

ANDORNO, Roberto. La bioéthique et la dignité de la personne. Paris: PUF, 1996.

ATLAN, Henri. Les Étincelles de Hasard - Trad. As Centelhas de Acaso. Paris: Éditions du Seuil, 1999.

BATESON, Gregory, Os homens são como a Planta. A Biologia e uma Teoria do Conhecimento. Cap. 1 Os Homens são como a Planta. In Gaia - Uma Teoria do Conhecimento. Willian I. Thompson (Org.). São Paulo: Editora Gaia, 1990.

BERNARD, Jean. De la biologie à l'éthique. Trad, Da Biologia à Ética. Bioética: Os novos poderes da ciência. Os novos deveres do Homem. Campinas SP: Ed. Psy, 1994.

BERSON, Henri. La Pénsée et le Mouvant. Paris: PUF. 1931 35ª 1960.

DAMÁSIO, Antônio. O Erro de Descartes - Emoção, Razão e Cérebro humano. São Paulo: Cia. das Letras, 1996.

ESPINOSA, Baruch. Etica more geométrico demonstrata. Coleção Pensadores.

FOUREZ, Gerard. A Construção das Ciências. Introdução à Filosofia e à Etica das ciências. S. Paulo: UNESP, 1995.

FOUCAUALT, Michel. Microfísica do Poder. Rio de Janeiro; Edições Graal, 1979.

FOUCAUALT, Michel. Surveiller et Punir. Paris: Gallimard, 1975.

HABERMAS, Jürgen. Consciência Moral e Agir Comunicativo. Rio de Janeiro: Tempo Brasileiro. 1989.

HORKHEIMER, Max. Eclipse da Razão. Rio de Janeiro: Labor. 1976.

HUSSERL, Edmund. Reccherches Logiques I Prolégomènes à la Logique Pure. Paris: PUF, 1969.

JACOB, François. La souris, la mouche et I'homme. Paris: Ed. Odile Jacob, 1997.

KANT, Emmanuel. Crítica da Razão Prática. Coleção Pensadores.

LORENZ, Konrad. Der Abbau des Menschlichen. Verlang München.1983. Trad. A Demolição do Homem (deveria ser do humano). Ed. Brasiliense.

MAFFESOLI, Michel. A Comunicação Pós-Moderna como Cultura, In Textos Comunicação e Pós-Modernidade. N. 28 Salvador: Bahia. 1992.

MATURANA, Humberto. Emoções e Linguagem na Educação e na Política. Belo horizonte: Ed. UFMG,.2009. 
MATURANA, Humberto. VARELA, Francisco. De Máquinas e Seres Vivos Autopoiese: A Organização do Vivo. Porto Alegre: Artes Médicas, 1997.

MERLEAU-PONTY, Maurice. Phénoménologie de la Perception. Paris: Gallimard, 1945.

MONOD, Jacques. O Acaso e a Necessidade. Petrópolis, RJ: Ed. Vozes, 1976.

OVERBYE, Dennis. Corações Solitários do Cosmos. São Paulo: Mercuryo, 1993

PORTER, Roy. História do Corpo. In Burke Peter (org.) A Escrita da História - Novas Perspectivas. Campinas SP: UNESP, 1992.

SAINT EXUPÉRY, Antoine de. O Pequeno Príncipe. Rio de Janeiro: Agir. 1964

TROCMÉ-FABRE, Hélène. Reinventar o Ofício de Aprender. São Paulo: TRION, 2010

VIGARELLO, Georges. Le corps redressé - Histoire d'un pouvoir pédagique. Paris: Delarge, éditeur. 1978.

\section{O ESPACIO DE LA ÉTICA EN LA EDUCACIÓN FÍSICA}

RESUMEN: Este estudio presenta como tema central la ética, acompañada de discusiones acerca de profesionalismo y producción del conocimiento. El alcance del tema abre puertas para muchas entradas, para subrayar diferentes aspectos, para desenvolver diferentes interpretaciones y metodologías. La opción, aquí presentada, favorece el tema de la ética inserido en el espacio de la educación física. El profesionalismo y la producción del conocimiento son partes fundamentales en el espacio de la educación física, evidentemente, descritos a partir de la ética. La primera referencia para la presentación de los temas es la filosofía, o, mejor dicto, un ejercicio de filosofar. Para eso, son tratadas dos cuestiones principales: qué se entiende cuando se habla la palabra ética? Y lo qué se necesita saber para que la ética pueda ocupar un espacio en la educación física?

Palabras-Chávez: Ética. Profesionalismo. Producción del conocimiento. Educación Física. 


\section{THE SPACE OF ETHICS IN PHYSICAL EDUCATION}

ABSTRACT: This study has ethics as the central issue, followed by discussions on professionalism and knowledge production. The wide scope of the theme opens doors for many entries, such as underlining different aspects or developing new comprehensions and methodologies. The option chosen here privileges the ethics inserted in the Physical Education space. The professionalism and knowledge production are important parts in the Physical Education space, evidently described through ethics. The first reference for the presentation of the themes is philosophy, or better off, a philosophy exercise. For that, the main issues are: what do we understand when we say the word ethics? What do we need to know so that ethics can occupy a space in Physical Education?

Key words: ethics, professionalism, knowledge production, Physical Education. 